\title{
Integrin Beta-3 Gene Polymorphism and Risk for Myocardial Infarction in Premature Coronary Disease
}

\author{
Mehrdad Sheikhvatan ${ }^{1}$, Mohammad Ali Boroumand ${ }^{1, *}$, Mehrdad Behmanesh ${ }^{2}$, Shayan Ziaee ${ }^{1}$, Sara \\ Cheraghee $^{1}$
}

${ }^{1}$ Tehran Heart Center, Tehran University of Medical Sciences, Tehran, Iran

${ }^{2}$ Tarbiat Modarres University, Tehran, Iran

* Corresponding author: Mohammad Ali Boroumand, MD, Tehran Heart Center, Tehran University of Medical Sciences, Tehran, Iran; Telefax: +982188029256; E-mail: borumand@razi.tums.ac.ir

\begin{abstract}
Background: Contradictory results have been obtained regarding the role of integrin, beta 3 (ITGB3) gene polymorphisms in occurrence of myocardial infarction (MI).

Objectives: We aimed to assess the association between $1565 \mathrm{C} / \mathrm{T}$ polymorphism of ITGB3 gene and increased risk for acute $\mathrm{MI}$ in patients with premature coronary artery disease (CAD).

Material and Methods: Our study included 1000 premature CAD patients that classified into two groups with history of MI $(n=461)$ and without of MI $(n=539)$. The polymorphism variants in $10 \%$ of samples were determined by PCRRFLP technique and genotyping of the polymorphism in all subjects was conducted by High Resolution Melting method. Given the two conditions of patients residing in Tehran and also faced with their first episode of MI, 640 out of 1000 study samples that had been previously followed-up were assessed in a retrospective cohort phase regarding long-term major adverse cardiac events (MACE).

Results: There was no significant difference in the frequency of $1565 \mathrm{C} / \mathrm{T}$ polymorphism between the MI and non-MI groups. The frequency of wild genotype was $69.2 \%$ and $72.2 \%$, the frequency of homozygous genotype was $21.3 \%$ and $18.4 \%$, and the frequency of mutant genotype was $9.5 \%$ and $9.5 \%$, respectively $(\mathrm{P}=0.505)$. No significant difference was also found in total-MACE free survival rate between the patients with different genotypes of $1565 \mathrm{C} / \mathrm{T}$ polymorphism in both $\mathrm{MI}$ and non-MI group.

Conclusions: The carriage of the $1565 \mathrm{C} / \mathrm{T}$ polymorphism of ITGB3 gene seems unlikely to be a significant risk factor for the development of MI in Iranian patients with premature CAD.

Keywords: Coronary Artery Disease; Myocardial Infarction, Genetics; Atherosclerosis
\end{abstract}

\section{Background}

Coronary artery disease and myocardial infarction as its major complication are clinical important manifestations of a chronic pathomorphological process in the coronary artery wall result of interaction between genetic and environmental factors (1). In this regard, these factors are associated with a number of cardiovascular disease risk factors such as hypercholesterolemia, hypertension, diabetes mellitus and smoking dependency. Accordingly, both internal factors (including genetic) and external factors (such as poor nutrition, physical inactivity and inappropriate treatment approaches) are directly effective on the development of atherosclerosis in the artery wall or indirectly by affecting the cardiovascular risk factors (2). At the cellular level, atherosclerosis involves a complex process that is mainly manifested with vascular endothelial dysfunction, lipid accumulation, migration and replacement of circulating blood cells such as platelets, smooth muscle proliferation, calcification, inflammation, and ultimately thrombus formation. Also, adhesion and aggregation of platelets on the damaged atherosclerotic plaques has an important role in the occurrence of acute myocardial infarction in patients with coronary heart disease. In this context, the role of genetic factors has been potentially confirmed and each of the above processes has been revealed to be associated with underlying genetic factors (3). Therefore, assessment of the family history of coronary heart disease has consistently emphasized on the role of genetic factors in these conditions so family history of 
disease was observed in $20 \%$ to $30 \%$ of affected patients (4). In this context, genetic variation affecting the occurrence and risk of coronary heart disease is common in various populations $(1,5)$. On this basis, the presence of the risk allele, genetic risk factors, or diseasecausing mutations have an important role in the occurrence of coronary heart disease that also emphasize some familial occurrence of the disease.

One of the important components of atherosclerosis and thrombosis formation is migration and replacement of some blood cells such as platelets. These cells cause the formation of atheroma plaque with activation, aggregation and adhesion to endothelial walls, beginning to cause coronary atherosclerosis (6). Also, by accumulating on atherosclerotic plaque damage, it can predispose the patients to occur acute myocardial infarction (7). Occurrence of atherosclerotic lesions mainly depends on arterial wall properties such as plaque lesion size, severity of coronary blood flow and more importantly on arterial wall susceptibility for coagulability. In this regard, the role of platelets is well established as an important component in the process of atherosclerosis and the occurrence of its complications such as acute myocardial infarction (8). This role has been confirmed by approving the effectiveness of antiplatelet therapy in patients susceptible to or suffering from atherosclerosis. In other words, platelet inhibitors have been very successful in preventing atherothrombotic complications such as myocardial infarction or angina (9).

By reviewing the literature and assessing the genes encoding the platelet surface receptors involved in platelet adhesion and aggregation processes (two main requirements of platelet activity in genesis of arterial plaques), the ITGB3 (integrin, beta 3 (platelet glycoprotein IIIa, antigen CD61) gene located on chromosome 17q21.32 was identified as an involved gene in the process of platelet adhesion and aggregation on atherosclerotic plaque. This gene consists of 2367 nucleotides encoding the glycoprotein GP IIIa receptors on the platelet surface that play a major role in the process of platelet adhesion on arterial endothelial surface. GP IIb/IIIa complex is a specific receptor for the binding of von Willebrand Factor and Fibronectin. In fact, this receptor plays an important role in regulation of platelet adhesion and aggregation that are the final process in platelet mass formation at the site of vascular injury. Because platelet adhesion and aggregation is a main arm of coronary atherosclerosis leading cardiac ischemic events, identifying gene polymorphisms triggering these thrombosis inducing processes is essential. Moreover, although the central role of ITGB3 gene polymorphisms in activating coronary atherosclerosis process has been clearly shown in some populations, the role of these polymorphisms in our population remains obscure. Additionally, the contradictory results have been obtained regarding the role of this gene and its-related polymorphisms in occurrence of acute myocardial infarction among different populations whole of the world.

\section{Objective}

In the current study, we aimed to assess the association between one of the main identified single nucleotide polymorphisms (SNPs) in ITGB3 gene (1565C/T) and increased risk for acute myocardial infarction in patients who suffered premature coronary artery disease in Iranian population.

\section{Materials and Methods}

\subsection{Study Population}

The present study was a part of a larger project initiated in 2009 aimed at identifying genetic risk factors predisposing to premature coronary artery disease among Iranian population running at the Tehran Heart center, a referral center for cardiovascular disorders from all regions of the country. By referring the angiography database of the Tehran heart center, the baseline information of all consecutive patients with the final diagnosis of premature coronary artery disease admitted from 2008 to 2011 were recorded at the study checklist including 492 men and 508 women aged 21 to 55 years. In other word, the considered coronary event was considered premature if it occurred before the age of 45 years in men and before 55 year of age in female. Those with incomplete information recorded in the database or inaccessible to complete this information were not included. According to a history of MI, patients were classified into two groups with history of MI ( $\mathrm{n}=$ $461)$ and without of MI $(n=539)$. In this regard, myocardial infarction was defined based on the Third Universal Definition of Myocardial Infarction requires cardiac myocyte necrosis with an increase and/or a decrease in a patient's plasma of cardiac troponin (cTn) with at least one cTn measurement greater than the 99(th) percentile of the upper normal reference limit with at least one of the following: 1) Symptoms of ischaemia, 2) New or presumed new significant STsegment-T wave (ST-T) changes or new left bundle branch block (LBBB), 3) Development of pathological Q waves in the ECG, 4) Imaging evidence of new loss of viable myocardium or new regional wall motion abnormality, and 5) Identification of an intracoronary thrombus by angiography or autopsy (10). Baseline information for this study was retrospectively developed based on collected and organized data in the angiography database of the center including information of admitted patients referred within the last 10 years. These data included demographics; anthropometric parameters; coronary artery risk factors including current smoking history (patients regularly smokes a tobacco product/products one or more times per day or has smoked in the 30 days prior to admission) (11), hypercholesterolemia (total cholesterol $\geq 200$ $\mathrm{mg} / \mathrm{dl}$, HDL-cholesterol $\leq 40 \mathrm{mg} / \mathrm{dl}$, triglycerides $\geq 150$ 
$\mathrm{mg} / \mathrm{dl}$ ) (12), family history of CAD (first degree relatives before the age of 55 in men and 65 years in women) (13), hypertension (systolic blood pressure $\geq 140 \mathrm{mmHg}$ and/or diastolic $\geq 90 \mathrm{mmHg}$ and/or on anti-hypertensive treatment) (14), diabetes mellitus (the use of insulin or a hypoglycemic agent, a fasting plasma glucose level of $126 \mathrm{mg} / \mathrm{dL}$ or more, or a 2-hour post-load plasma glucose level of $200 \mathrm{mg} / \mathrm{dL}$ or more (15); left ventricular ejection fraction, and the number of involved coronary vessels according to angiography results. The institutional review boards of the Tehran University of Medical Sciences approved the study protocol.

\subsection{Genetic Analysis}

Genomic DNA was extracted from peripheral blood samples of participants using a standard salting-out method consisted of the following steps: cell lysis by Sodium dodecyl sulfate (SDS) solution, denaturation of nucleoproteins and inactivation of cellular enzymes by Proteinase $\mathrm{K}$, removal of contaminants with sodium chloride, and DNA precipitation by ethanol $70 \%$. The polymorphism of the ITGB3 gene was analyzed on the basis of polymerase-chain-reaction (PCR) amplification (Fig. 1).

A post PCR RFLP assay was performed to detect $1565 \mathrm{C} / \mathrm{T}$ polymorphism. In this context, PCR was performed with a $25 \mu \mathrm{L}$ reaction mixture containing 0.5 $\mu \mathrm{L}$ of DNA, $0.6 \mu \mathrm{M}$ of each primer, and $12.5 \mu \mathrm{M}$ of Taq PCR Master Mix (Sinaclon Co., Tehran, Iran). Amplification was carried out using primers F 5'CCTAGGCTGGTCTTGAACTCTTGG-3', and R5'ACTCACTGGGAACTCGATGG-3' (Bioneer co. South Korea) and then digested by restriction enzyme Msp I (Fermentas Co., Lithuania) with the $C^{\wedge}$ CGG restriction site. The digested products were then visualized on $3 \%$ agarose gel stained with ethidium bromide. Amplification by PCR-RFLP was performed to determine three kinds of genotype patterns by comparing different patterns of restriction fragments for each amplified PCR product using the restriction enzyme for digestion (Fig. 2).

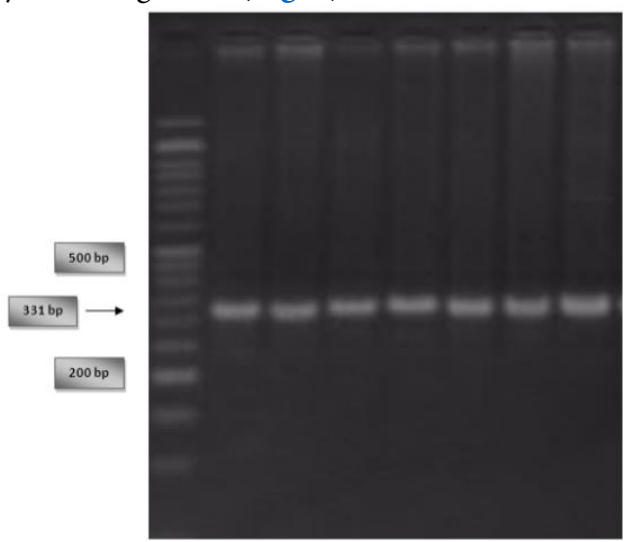

Figure 1. Polymerase-chain-reaction (PCR) amplification of $1565 \mathrm{C} / \mathrm{T}$ polymorphism of the ITGB3 gene (Agarose gel electrophoresis of DNA (2\% agarose); PCR-based assay amplified a $331 \mathrm{bp}$ product, the 50-bp molecular size marker)

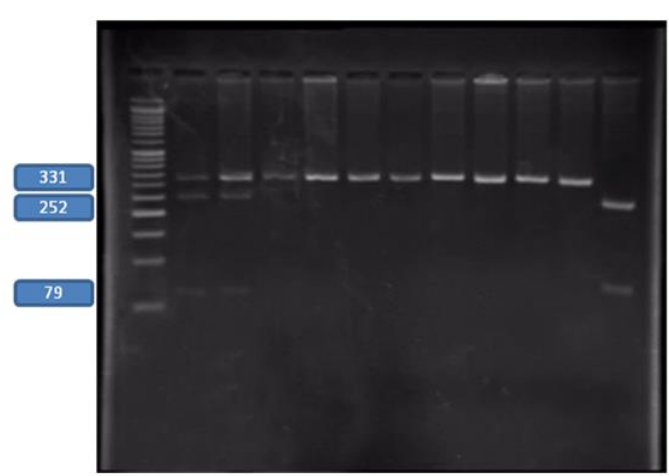

Figure 2. PCR-RFLP analysis with Msp I for $1565 \mathrm{C} / \mathrm{T}$ polymorphism to determine polymorphism variants (Agarose gel electrophoresis of DNA ( $2 \%$ agarose); PCR-based assay amplified $331 \mathrm{bp}$ product and $252 \mathrm{bp}$ and $79 \mathrm{bp}$ products after effect of MspI enzyme with the restriction site of $\mathrm{C}^{\wedge} \mathrm{CGG}$, the 50-bp molecular size marker)

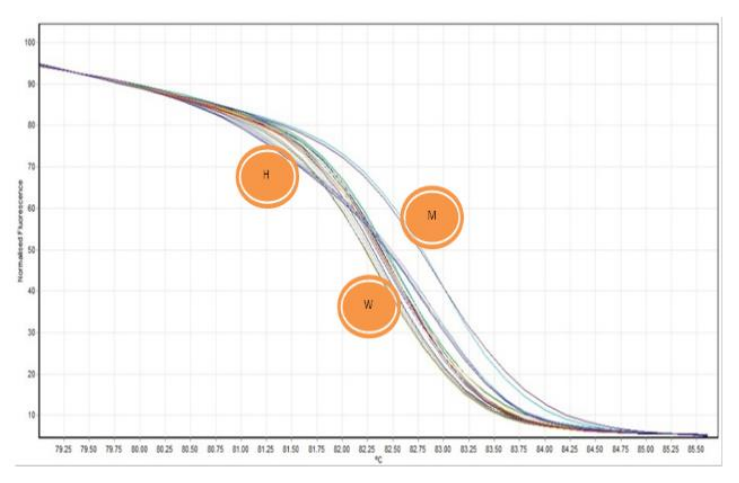

Figure 3. High resolution melting genotyping of the $1565 \mathrm{C} / \mathrm{T}$ polymorphism

After discovering the patterns of the polymorphism genotypes by PCR-RFLP technique in $10 \%$ of samples and determining genomic variants, we used these patterns as the samples for genotyping all study samples by employing high resolution melting (HRM) technique (Fig. 3). In our study, the patterns of the genotypes of each sample were determined as wide, heterozygous, or mutant by HRM technique using specific primers $F$ 5'AGCTCTGATTGCTGGACTTC -3', and R5'ACTCACTGGGAACTCGATG -3’ (Bioneer co. South Korea).

In final step and to examine the relationship of polymorphism with the serum level of gene product, the serum level of Human beta-3 Integrin was measured using ELISA kit (no. CSB-EL011885HU, Wuhan Hitech, China).

\subsection{Follow-up Step}

Given the two conditions of patients residing in Tehran and also faced with their first episode of MI, 640 out of 1000 study samples that had been previously followedup with a median follow-up time 45.74 months regarding long-term major adverse cardiac events (MACE) were enrolled in this retrospective cohort phase. Our purpose in this phase was to assess clinical 
consequences of premature $\mathrm{CAD}$ in $\mathrm{MI}$ and non-MI groups as well as to determine the value of ITGB3 gene polymorphism to predict this outcome. In this step, total MACE was defined as the presence of at least one of the following events: mortality, cardiac interventions such as coronary artery bypass grafting (CABG) or percutaneous coronary intervention (PCI), or any new coronary involvement defined as involvement of new coronary vessels or progression of involvement in previous diseased coronary vessels in accordance with coronary angiography.

\subsection{Statistical Analysis}

Data were analyzed using IBM SPSS statistical software version 21.0 (Armonk, NY: IBM Corp.). Quantitative variables were presented as mean \pm standard deviation, and categorical variables were presented by absolute frequencies and percentages. Continuous variables were compared using $t$ test. Whenever the data did not appear to have normal distribution, Mann- Whitney U test was used. Categorical variables were compared using chisquare test. Fisher exact test was used when more than $20 \%$ of cells with expected count of less than 5 had been observed. The multivariate logistic regression model was employed to determine association between $1565 \mathrm{C} / \mathrm{T}$ polymorphism and occurrence of MI with the presence of confounders. The Cox proportional hazard model was used to analyze the association between the existence of gene polymorphism and total-MACE in both MI and non-MI groups and the hazard ratios were then displayed. Total-MACE free survival rate was assessed using Kaplan-Mayer curve analysis. P values of $\leq 0.05$ were considered statistically significant.

\section{Results}

The final study population consisted of 1000 individuals with premature $\mathrm{CAD}$ classified in $\mathrm{MI}$ group (mean age $43.78 \pm 5.61$ years, male $66.2 \%$ ) and non-MI group (mean age $47.00 \pm 5.70$ years, male $34.7 \%$ ). Overall, $35.1 \%$ of participants reported to have family history of $\mathrm{CAD}, 51.9 \%$ had history of hypertension, $72.5 \%$ had history of hyperlipidemia, $32.7 \%$ suffered diabetes mellitus, and $29.7 \%$ were current smoker. The two groups with and without MI were similar in family history of $\mathrm{CAD}$, however there were significant differences in other baseline characteristics including gender and age distribution, as well as cardiovascular risk factors (Table 1). Participants in MI group were more likely to be younger and male and also had lower left ventricular ejection fraction. The MI group had more severe coronary artery involvement that single vessel disease was found in $47.9 \%$ of MI patients and $54.4 \%$ of non-MI patients, while three-vessel disease was revealed in $28.9 \%$ and $20.4 \%$, respectively.

Table 1. Baseline characteristics and clinical data in both myocardial infarction and non-myocardial infarction groups

\begin{tabular}{|c|c|c|c|}
\hline Characteristics & MI group & Non-MI group & $p$ value \\
\hline & $(n=461)$ & $(n=539)$ & \\
\hline Gender & & & $<0.001$ \\
\hline Male & $305(66.2)$ & $187(34.7)$ & \\
\hline Female & $156(33.8)$ & $352(65.3)$ & \\
\hline Age, year & $43.78 \pm 5.61$ & $47.00 \pm 5.70$ & 0.004 \\
\hline Body mass index, $\mathrm{kg} / \mathrm{m}^{2}$ & $29.06 \pm 4.71$ & $30.26 \pm 5.36$ & 0.017 \\
\hline \multicolumn{4}{|l|}{ Medical history } \\
\hline Family history of coronary artery disease & $156(33.8)$ & $195(36.2)$ & 0.440 \\
\hline Current smoking & $195(42.3)$ & $102(18.9)$ & $<0.001$ \\
\hline Hyperlipidemia & $310(67.2)$ & $415(77.0)$ & 0.001 \\
\hline Hypertension & $206(44.7)$ & $313(58.1)$ & $<0.001$ \\
\hline Diabetes mellitus & $119(25.8)$ & $208(38.6)$ & $<0.001$ \\
\hline Opium use & $102(22.1)$ & $46(8.5)$ & $<0.001$ \\
\hline \multicolumn{4}{|l|}{ Oral medication } \\
\hline Aspirin & $437(94.8)$ & $467(86.6)$ & $<0.001$ \\
\hline Beta-blockers & $412(89.4)$ & $402(74.6)$ & $<0.001$ \\
\hline Nitrate & $395(85.7)$ & $376(69.8)$ & $<0.001$ \\
\hline Calcium blocker & $51(11.1)$ & $92(17.1)$ & 0.007 \\
\hline Anti-hyperlipidemic & $30(6.5)$ & $31(5.8)$ & 0.618 \\
\hline Anti-hyperglycemic & $71(15.4)$ & $136(25.2)$ & $<0.001$ \\
\hline Digoxin & $10(2.2)$ & $8(1.5)$ & 0.417 \\
\hline Diuretics & $37(8.0)$ & $53(9.8)$ & 0.320 \\
\hline Angiotensin-converting-enzyme (ACE)-inhibitor & $312(67.7)$ & $238(44.2)$ & $<0.001$ \\
\hline Number of involved coronary arteries & & & 0.005 \\
\hline One vessel & $221(47.9)$ & $293(54.4)$ & \\
\hline Two vessels & $107(23.2)$ & $136(25.2)$ & \\
\hline Three vessels & $133(28.9)$ & $110(20.4)$ & \\
\hline Left ventricular ejection fraction, $\%$ & $46.52 \pm 10.14$ & $55.58 \pm 7.98$ & $<0.001$ \\
\hline \multicolumn{4}{|l|}{ Serum laboratory markers } \\
\hline Total cholesterol, mg/dl & $182.92 \pm 53.81$ & $193.82 \pm 49.25$ & 0.891 \\
\hline Triglyceride, mg/dl & $170.0(132.0-228.5)$ & $160.0(117.5-223.0)$ & 0.040 \\
\hline Low density lipoprotein, mg/dl & $106.0(84.0-131.5)$ & $118.0(91.0-149.0)$ & $<0.001$ \\
\hline High density lipoprotein, mg/dl & $38.04 \pm 10.23$ & $42.68 \pm 11.21$ & 0.047 \\
\hline Fasting blood sugar, & $101.0(90.0-122.0)$ & $104.0(93.0-149.0)$ & 0.003 \\
\hline Creatinine, & $0.9(0.8-1.1)$ & $0.8(0.7-1.0)$ & $<0.001$ \\
\hline
\end{tabular}


Table 2. Multivariable logistic regression analysis to determine association between $1565 \mathrm{C} / \mathrm{T}$ polymorphism and occurrence of myocardial infarction

\begin{tabular}{lccc}
\hline Item & Multivariate $\boldsymbol{p}$ value & Odds Ratio & 95\% Confidence Interval \\
\hline 1565C/T polymorphism & & & \\
Wild genotype & 0.667 & 1.000 & Reference \\
\hline Heterozygous genotype & 0.370 & 1.204 & $0.802-1.809$ \\
Mutant genotype & 0.950 & 1.017 & $0.594-1.741$ \\
\hline Male gender & 0.006 & 2.007 & $1.224-3.290$ \\
\hline Current smoking & 0.025 & 1.558 & $1.059-2.292$ \\
Hyperlipidemia & 0.267 & 0.809 & $0.561-1.167$ \\
Hypertension & 0.630 & 1.090 & $0.767-1.551$ \\
\hline Diabetes mellitus & 0.274 & $0.549-1.185$ \\
\hline Aspirin use & 0.524 & $0.632-2.462$ \\
\hline Beta-blocker use & $<0.001$ & $1.819-5.177$ \\
\hline Nitrate use & 0.010 & $1.150-2.788$ \\
\hline Calcium use & 0.672 & 3.069 & $0.576-1.427$ \\
Three vessel disease & 0.050 & 1.790 & $1.001-2.184$ \\
\hline Age & 0.049 & 0.907 & $0.922-1.000$ \\
\hline Body mass index & 0.707 & 1.478 & $0.973-1.041$ \\
\hline Left ventricular ejection fraction & $<0.001$ & 0.960 & $0.876-0.910$ \\
\hline Serum creatinine & 0.120 & 1.006 & $0.917-2.107$ \\
\hline
\end{tabular}

Table 3. Review of the literature on association between $1565 \mathrm{C} / \mathrm{T}$ polymorphism and occurrence of myocardial infarction in coronary artery disease patients

\begin{tabular}{lccccc}
\hline Author & Country & Year of publish & Number of patients & Association between polymorphism and myocardial infarction \\
\hline Gardemann (16) & Germany & 1998 & 2252 & No \\
Pastinen (17) & Finland & 1998 & 302 & Yes \\
Chudakova (18) & Russia & 2004 & 135 & No \\
Knowles (19) & US & 2007 & 1375 & No \\
Addad (20) & Tunisia & 2010 & 188 & Yes \\
Makeeya (21) & Russia & 2013 & 165 & No & No \\
Verdoia (22) & Italy & 2014 & 478 & No \\
Our study & Iran & 2014 & 1000 & & \\
\hline
\end{tabular}

There was no significant difference in the frequency of $1565 \mathrm{C} / \mathrm{T}$ polymorphism of ITGB3 gene between the MI and non-MI groups so that the frequency of wild genotype was $69.2 \%$ and $72.2 \%$, the frequency of homozygous genotype was $21.3 \%$ and $18.4 \%$, and the frequency of mutant genotype was $9.5 \%$ and $9.5 \%$, respectively $(\mathrm{P}=0.505)$. Results were also similar when adjusted for covariates in a multivariate logistic regression analysis (adjusted $\mathrm{OR}=1.204, \mathrm{p}=0.370$ for heterozygous genotype and adjusted $\mathrm{OR}=1.017, \mathrm{P}=$ 0.950 for mutant genotype (Table 2). Regarding the level of Human beta-3 Integrin, the serum level of this marker in MI group was $298.66 \pm 112.64 \mathrm{mg} / \mathrm{dl}$ and in non-MI group was $247.82 \pm 107.09 \mathrm{mg} / \mathrm{dl}$ that was higher in former group $(\mathrm{P}=0.032)$.

The median for survival time for participants in MI group $(\mathrm{n}=250)$ was 44.55 months and in non-MI group $(\mathrm{n}=304)$ was 46.92 months. No significant difference was found in total-MACE free survival rate between the patients with different genotypes of $1565 \mathrm{C} / \mathrm{T}$ polymorphism in MI group (HR = 1.202, 95\%CI: 0.648 $-2.230, \mathrm{P}=0.559$ for homozygous genotype and $\mathrm{HR}=$ 2.061, 95\%CI: $0.950-4.475, \mathrm{P}=0.067$ for mutant genotype), and also in non-MI group ( $\mathrm{HR}=0.879$, 95\%CI: $0.426-1.816, \mathrm{P}=0.728$ for homozygous genotype and $\mathrm{HR}=2.239,95 \% \mathrm{CI}: 0.791-6.339, \mathrm{p}=$ 0.129 for mutant genotype).

\section{Discussion}

The results presented here appear not to demonstrate an increased risk of myocardial infarction in Iranian carriers of the $1565 \mathrm{C} / \mathrm{T}$ polymorphism of ITGB3 gene. Also, the presence of this polymorphism could not predispose carriers to future adverse outcome in both $\mathrm{CAD}$ groups with and without experience of myocardial infarction. Reviewing the literature (16-22) achieves conflicting results in the association between $1565 \mathrm{C} / \mathrm{T}$ polymorphism and occurrence of acute myocardial infarction in various populations indicating the central role of ethnicity in triggering cardiac ischemic event following appearance of this gene polymorphism (Table 3).

Despite a few association studies conducted whole of the world, it seems that significant association between $1565 \mathrm{C} / \mathrm{T}$ polymorphism of ITGB3 gene and myocardial infarction in $\mathrm{CAD}$ patients may be more found-out in north Europe and also in African societies as well shown in the studies by Pastinen et al. (16) and Addad et al. (19) that was not reveal in similar studies in other regions such as west Europe, north America, or Asia. However, the results may be influenced by potential biases such as small samples sizes and ignoring potential underlying confounders. Overall, our study could show that the presence of $1565 \mathrm{C} / \mathrm{T}$ polymorphism is neither associated with increased risk for myocardial infarction nor is able to predict long-term ischemic events or need to cardiac interventions.

One of the main reasons for the obtained insignificant association is polygenic nature of the etiology of cardiovascular risk while a complex and strong polygenic interaction was demonstrated between the 
increase risk for cardiac ischemic events and environmental factors leading a synergistic manner $(23,24)$. Some studies could reveal this synergistic effect induced by smoking so that smoking adds to carriage of the $1565 \mathrm{C} / \mathrm{T}$ prominent allele was accompanied with higher risk for cardiovascular disease when compared to non-smoking $1565 \mathrm{C} / \mathrm{T}$ homozygote (25-28). Furthermore, the link between increased plasma lipids and increased risk for coronary artery disease in those subjects with $1565 \mathrm{C} / \mathrm{T}$ polymorphism could be noted (29). Interestingly, Grove et al showed that the relationship between carriage of the $1565 \mathrm{C} / \mathrm{T}$ prominent allele and myocardial infarction decreased as cholesterol levels increased, suggesting that the true effect of this allele may be diluted and hence concealed by the concomitant presence of conventional risk factors (26). However, this hypothesis is not supported by the data analyzed within the present study by deleting confounding effects of conventional cardiac risk factors in a multivariate regression model.

The main interesting and unique point of the present association study was that we focused the special age subgroups of premature $\mathrm{CAD}$ patients might face early myocardial infarction. On the other hand, because of low age of $\mathrm{CAD}$ among our population, a substantial number of our patients' recorded data were devoted to young subjects who suffered premature CAD. To the best of our knowledge, this is first study on association between $1565 \mathrm{C} / \mathrm{T}$ polymorphism of ITGB3 gene and risk for myocardial infarction in premature $\mathrm{CAD}$ patients. It can be considered as strengthen of the current study. On the other hand, possession of a genetic treasure of premature $\mathrm{CAD}$ patients was not possible in many previous studies. Providing such an opportunity for us led to performing the present study with high power. Moreover, our study was the first in our community with the high ethnic diversity. However, because our center is a referral center for the entire country, our results can be generalized to the whole regions of the country.

\section{Conclusions}

In conclusion, the carriage of the $1565 \mathrm{C} / \mathrm{T}$ polymorphism of ITGB3 gene seems unlikely to be a significant risk factor for the development of myocardial infarction in Iranian patients with premature CAD. Also, the presence of this ITGB3 gene polymorphism may not predict cardiac events or the need for cardiac interventions in the future.

\section{Acknowledgement}

All authors contributed to refinement and approved the final manuscript. The study was supported by the Tehran University of Medical Sciences. The authors have no conflict of interest.

\section{References}

1. Banerjee A. A review of family history of cardiovascular disease: risk factor and research tool. Int J Clin Pract. 2012;66(6):536-543. doi: 10.1111/j.17421241.2012.02908.x pmid: 22607505

2. McGillicuddy FC, Roche HM. Nutritional status, genetic susceptibility, and insulin resistance--important precedents to atherosclerosis. Mol Nutr Food Res. 2012;56(7):1173-1184. doi: 10.1002/mnfr.201100785 pmid: 22760984

3. Roberts R, Stewart AF. The genetics of coronary artery disease. Curr Opin Cardiol. 2012;27(3):221-227. doi: 10.1097/HCO.0b013e3283515b4b pmid: 22382499

4. Scheuner MT. Clinical application of genetic risk assessment strategies for coronary artery disease: genotypes, phenotypes, and family history. Prim Care. 2004;31(3):711-737, xi-xii. doi: 10.1016/j.pop.2004.04.001 pmid: 15331255

5. Roberts R, Stewart AF. 9p21 and the genetic revolution for coronary artery disease. Clin Chem. 2012;58(1):104-112.

10.1373/clinchem.2011.172759 pmid: 22015375

6. Sharma RK, Voelker DJ, Sharma R, Reddy HK, Dod H, Marsh JD. Evolving role of platelet function testing in coronary artery interventions. Vasc Health Risk Manag. 2012;8:65-75. doi: 10.2147/VHRM.S28090 pmid: 22371653

7. Lordkipanidze M. Platelet turnover in atherothrombotic disease. Curr Pharm Des. 2012;18(33):5328-5343. pmid: 22724418

8. Freynhofer MK, Bruno V, Wojta J, Huber K. The role of platelets in athero-thrombotic events. Curr Pharm Des. 2012;18(33):5197-5214. pmid: 22724408

9. Fintel DJ. Oral antiplatelet therapy for atherothrombotic disease: overview of current and emerging treatment options. Vasc Health Risk Manag. 2012;8:77-89. doi: 10.2147/VHRM.S26030 pmid: 22393298

10. Reddy K, Khaliq A, Henning RJ. Recent advances in the diagnosis and treatment of acute myocardial infarction. World J Cardiol. 2015;7(5):243-276. doi: 10.4330/wjc.v7.i5.243 pmid: 26015857

11. Barrett-Connor E, Giardina EG, Gitt AK, Gudat U, Steinberg HO, Tschoepe D. Women and heart disease: the role of diabetes and hyperglycemia. Arch Intern Med. 2004;164(9):934-942.

doi: 10.1001/archinte.164.9.934 pmid: 15136300

12. Wood D, De Backer G, Faergeman O, Graham I, Mancia G, Pyorala K. Prevention of coronary heart disease in clinical practice. Summary of recommendations of the Second Joint Task Force of European and other Societies on Coronary Prevention. J Hypertens. 1998;16(10):1407-1414. pmid: 9814610

13. Jomini V, Oppliger-Pasquali S, Wietlisbach V, Rodondi N, Jotterand V, Paccaud F, et al. Contribution of major cardiovascular risk factors to familial premature coronary artery disease: the GENECARD project. J Am Coll Cardiol. 2002;40(4):676-684. pmid: 12204497

14. James PA, Oparil S, Carter BL, Cushman WC, Dennison-Himmelfarb C, Handler J, et al. 2014 evidence-based guideline for the management of high blood pressure in adults: report from the panel members appointed to the Eighth Joint National 
Committee (JNC 8). JAMA. 2014;311(5):507-520. doi: 10.1001/jama.2013.284427 pmid: 24352797

15. American Diabetes A. Standards of medical care in diabetes--2013. Diabetes Care. 2013;36 Suppl 1:S1166. doi: $10.2337 / \mathrm{dc} 13-S 011$ pmid: 23264422

16. Haberbosch W, Rau M, Hehrlein FW, Tillmanns H, Philipp M, Katz N, et al. Association of the Platelet Glycoprotein IIIa PIA1/A2 Gene Polymorphism to Coronary Artery Disease but not to Nonfatal Myocardial Infarction in Low Risk Patients. Thrombosis Haemostasis. 2017;80(08):214-217. doi: 10.1055/s0037-1615174

17. Pastinen T, Perola M, Niini P, Terwilliger J, Salomaa V, Vartiainen E, et al. Array-based multiplex analysis of candidate genes reveals two independent and additive genetic risk factors for myocardial infarction in the Finnish population. Hum Mol Genet. 1998;7(9):14531462. pmid: 9700201

18. Tchoudakova DA, Minushkina LO, Zateyshchikov DA, Nosikov VV. Association of Polymorphic Marker A1/A2 of Gene ITGB3 with Coronary Artery Disease and Myocardial Infarction. Rus $J$ Genet. 2004;40(10):1156-1158.

doi:

10.1023/B:RUGE.0000044760.05694.d2

19. Knowles JW, Wang H, Itakura H, Southwick A, Myers $\mathrm{RM}$, Iribarren $\mathrm{C}$, et al. Association of polymorphisms in platelet and hemostasis system genes with acute myocardial infarction. Am Heart J. 2007;154(6):10521058. doi: 10.1016/j.ahj.2007.05.021 pmid: 18035074

20. Addad F, Elalamy I, Chakroun T, Abderrazek F, Dridi Z, Hamdi S, et al. Platelet glycoprotein IIIa (platelet antigen 1 /platelet antigen 2 ) polymorphism and 1-year outcome in patients with stable coronary artery disease. Blood Coagul Fibrinolysis. 2010;21(7):674-678. doi: 10.1097/MBC.0b013e32833e47c1 pmid: 20739877

21. Makeeva OA, Zykov MV, Golubenko MV, Kashtalap VV, Kuslish EV, Goncharova IA, et al. [The role of genetic factors in the prediction of myocardial infarction complications within one year follow up]. Kardiologiia. 2013;53(10):16-23. pmid: 24645551

22. Verdoia M, Secco GG, Cassetti E, Schaffer A, Barbieri L, Perrone-Filardi P, et al. Platelet PIA1/PIA2 polymorphism and the risk of periprocedural myocardial infarction in patients with acute coronary syndromes undergoing coronary angioplasty. Blood Coagul Fibrinolysis. 2014;25(2):107-113. doi: 10.1097/MBC.0b013e3283650717 pmid: 24480844

23. Marenberg ME, Risch N, Berkman LF, Floderus B, de Faire U. Genetic susceptibility to death from coronary heart disease in a study of twins. $N$ Engl J Med. 1994;330(15):1041-1046. doi: 10.1056/NEJM199404143301503 pmid: 8127331

24. Nora JJ, Lortscher RH, Spangler RD, Nora AH, Kimberling WJ. Genetic--epidemiologic study of earlyonset ischemic heart disease. Circulation. 1980;61 (3):503-508. pmid: 7353240

25. Ardissino D, Mannucci PM, Merlini PA, Duca F, Fetiveau R, Tagliabue L, et al. Prothrombotic genetic risk factors in young survivors of myocardial infarction. Blood. 1999;94(1):46-51. pmid: 10381497

26. Grove EL, Orntoft TF, Lassen JF, Jensen HK, Kristensen SD. The platelet polymorphism PIA2 is a genetic risk factor for myocardial infarction. $J$ Intern Med. 2004;255(6):637-644. doi: 10.1111/j.13652796.2004.01327.x pmid: 15147527

27. Lopes NH, Pereira AC, Hueb W, Soares PR, Lanz JR, Gersh BJ, et al. Effect of glycoprotein IIIa PlA2 polymorphism on outcome of patients with stable coronary artery disease and effect of smoking. Am J Cardiol. 2004;93(12):1469-1472. doi: 10.1016/j.amjcard.2004.03.005 pmid: 15194015

28. Schwartz E, Demidova D, Sirotkina O, Kudinov S. The combination of glycoprotein IIIa PIA polymorphism with polymorphism of serotonin transporter as an independent strong risk factor for the occurrence of coronary thrombosis. Mol Genet Metab. 2003;79(3):229-230. pmid: 12855229

29. Sentí M, Aubó C, Bosch M. The relationship betwen smoking and triglyceride-rich lipoproteins is modulated by genetic variation in the glycoprotein IIIa gene. Metabolism. 1998;47(9):1040-1041. doi: 10.1016/s0026-0495(98)90274-8 